\title{
EFEITOS DO THIDIAZURON E DO ÁCIDO GIBERÉLICO NAS CARACTERÍSTICAS DOS CACHOS E BAGOS DA UVA DE MESA 'VÊNUS' NA REGIÃo NOROESTE DO ESTADO DE SÃO PAULO'
}

\author{
RENATO VASCONCELOS BOTELHO \\ ERASMO JOSÉ PAIOLI PIRES ${ }^{2}$ \\ MAURILO MONTEIRO TERRA ${ }^{2}$ \\ STELLA CONSORTE CATO ${ }^{3}$
}

\begin{abstract}
RESUMO - O uso de reguladores de crescimento está amplamente difundido no cultivo da videira para a melhoria da qualidade das uvas (Vitis vinifera L.), visando principalmente ao aumento em tamanho e ao pegamento dos bagos, à descompactação dos cachos e à eliminação de sementes. Nesse contexto, um experimento foi conduzido em vinhedo do cultivar Vênus localizado em Urânia-SP, região noroeste de São Paulo, por dois ciclos consecutivos. Para os tratamentos, utilizam-se thidiazuron a 5 ou $10 \mathrm{mg} . \mathrm{L}^{-1}$ e ácido giberélico a $30 \mathrm{mg} . \mathrm{L}^{-1}$, combinados ou não. Foram avaliadas as seguintes variáveis: comprimento, largura e massa dos cachos e bagos; massa dos engaços; número de bagos; número de sementes-traço; e teor de sólidos solúveis totais, acidez total titulável e relação
\end{abstract}

SST/ATT do mosto. As aplicações de ácido giberélico aumentaram a massa, o comprimento, a largura e o número dos bagos, e reduziram o número de sementes-traço de uvas 'Vênus'. A associação de thidiazuron com ácido giberélico potencializou o efeito desse regulador de crescimento no aumento do pegamento dos frutos e na redução do número de sementes-traço. Aplicações de thidiazuron a $10 \mathrm{mg} . \mathrm{L}^{-1}$, associado ou não ao ácido giberélico, atrasaram a maturação da uva, diminuindo o teor de sólidos solúveis totais e a relação SST/ATT e reduziram a acidez total titulável do mosto. Aplicações de reguladores de crescimento também aumentaram a massa dos cachos e dos engaços.

TERMOS PARA INDEXAÇÃO: Vitis, videira, frutos, regulador de crescimento, giberelina, citocinina.

\section{EFFECTS OF THIDIAZURON AND GIBBERELLIC ACID ON CLUSTER AND BERRY CHARACTERISTICS OF 'VÊNUS' TABLE GRAPE IN THE NORTHWESTERN SÃO PAULO STATE}

\begin{abstract}
The use of growth regulators is widely diffused in vine crops to improve grapes quality (Vitis vinifera L.), aiming mainly the increase of fruit size and set, loosening clusters, and elimination of seeds. In this context, a trial was carried out in a vineyard located at Urânia-SP, Northwestern São Paulo State, during two seasons. It was used thidiazuron at 5 or $10 \mathrm{mg} . \mathrm{L}^{-1}$ and gibberellic acid at $30 \mathrm{mg} . \mathrm{L}^{-1}$, combined or not. The
\end{abstract}

following variables were evaluated: weight, length and width of clusters and berries; weight of rachis; number of berries; number of trace-seeds; and total soluble solids content, total titratable acidity, and TSS/TTA ratio of juice. Gibberellic acid applications increased weight, length, width and number of berries, and reduced number of trace-seeds. Association to thidiazuron potentiated gibberellic acid effects regarding

1. Parte da tese de doutorado do primeiro autor apresentada ao curso de pós-graduação em Agronomia da Faculdade de Ciências Agronômicas - UNESP, Campus de Botucatu, SP.

2. Engenheiro Agrônomo, Dr., Centro de Fruticultura, Instituto Agronômico de Campinas, Caixa Postal 28 13001-970 - Campinas, SP. Bolsista FAPESP.

3. Engenheiro Agrônomo, Dr. Centro de Fruticultura, Instituto Agronômico de Campinas. Bolsistas do CNPq.

4. Engenheiro Agrônomo, Mestranda do curso de pós-graduação, ESALQ/USP. Bolsista da FAPESP. 
the increase in the number of berries and reduction in the number of trace-seeds. Thidiazuron applications, associated or not to gibberellic acid, delayed fruit ripening, decreased total soluble solutes content and TSS/TTA ratio and increased total titratable acidity of juice. Growth regulators applications also increased weight of clusters and rachis.

INDEX TERMS: Vitis, vine, fruits, growth regulator, gibberellin, citokynin.

\section{INTRODUÇÃO}

O Estado de São Paulo aparece em posição de destaque dentro da viticultura brasileira. Com produção anual de 201.630 toneladas, em 11.553 hectares, representa $21,0 \%$ da produção nacional, sendo a maior parte do cultivo destinada à produção de uvas de mesa (AGRIANUAL, 2001). De acordo com Terra et al. (1998), entre as diferentes zonas produtoras do Estado, a região noroeste vêm apresentando incrementos significativos de produção a partir da década de 80, com colheitas concentradas entre junho e outubro.

As giberelinas são os reguladores de crescimento mais amplamente utilizados comercialmente em viticultura, visando principalmente ao aumento do tamanho e à fixação dos bagos, à descompactação dos cachos e à eliminação de sementes (Pires, 1998).

Pires et al. (1986) estudaram o efeito de diferentes doses de ácido giberélico sobre as características dos cachos da cultivar sem sementes, A Dona (IAC871-13), e verificaram que o tratamento a $20 \mathrm{mg} . \mathrm{L}^{-1}, 14$ dias após o florescimento, aumentou a massa, comprimento e largura dos cachos e dos bagos. Em vinhedos de 'Concord', onde ocorre queda precoce dos bagos, esse problema pode ser mimimizado aplicando-se solução aquosa de $\mathrm{AG}_{3}$ a $100 \mathrm{mg} . \mathrm{L}^{-1}, 11$ dias após o florescimento (Bukovac et al., 1960).

Para a cultivar Itália, Guerra et al. (1981) verificaram aumento do tamanho dos bagos, maior uniformidade dos cachos, pedicelos mais alongados, engrossados e rijos e menor número de sementes, mediante aplicação de ácido giberélico entre 10 e $20 \mathrm{mg} . \mathrm{L}^{-1}$, por ocasião da queda natural dos frutos.

O thidiazuron (N-fenil-N-1,2,3-tidiazol-5tiuréia) (TDZ) é uma citocinina sintética utilizada na cultura do algodoeiro para provocar desfolhamento e em cultura de tecidos para induzir brotação "in vitro" (Petri et al., 1992).

Em fruticultura, há trabalhos que comprovaram a eficiência do thidiazuron na quebra de dormência de gemas de macieira e pereira (Francisconi et al., 1992) e no aumento do tamanho e pegamento dos frutos de maçãs e kiwis (Petri et al., 1992; Schuck \& Petri, 1992).

Nas variedades de videiras sem sementes Sovereign Coronation, Simone, Selection 495 e Selection
535, Reynolds et al. (1992) estudaram os efeitos de aplicações de thidiazuron nas doses de 0,4 e 8 mg.L ${ }^{-1}$, quando os bagos atingiram $5 \mathrm{~mm}$ de diâmetro. Pelos resultados obtidos, verificaram que o thidiazuron aumentou linearmente a massa dos cachos e bagos e reduziu o teor de sólidos solúveis totais e o pH do mosto.

Por outro lado, Byun \& Kim (1995) trataram cachos de videiras da cultivar Kyoho com $\mathrm{AG}_{3}$ a $20 \mathrm{mg}$. $\mathrm{L}^{-}$ ${ }^{1}$ e thidiazuron a 5 ou $10 \mathrm{mg} . \mathrm{L}^{-1}$, cinco dias após o pleno florescimento, e verificaram que $\mathrm{AG}_{3}$ aumentou o tamanho dos bagos, enquanto o thidiazuron aumentou o número de bagos. Tratamentos combinados de thidiazuron e $\mathrm{AG}_{3}$ aumentaram o tamanho e o número de bagos. Entretanto, o thidiazuron reduziu a coloração dos bagos e o teor de sólidos solúveis totais.

Tendo em vista as possibilidades de utilização de reguladores de crescimento para a melhoria da qualidade de uvas, com este trabalho objetivou-se estudar os efeitos de aplicações de thidiazuron e ácido giberélico nas características dos cachos e bagos da uva 'Vênus' na região noroeste do Estado de São Paulo.

\section{MATERIAL E MÉTODOS}

O experimento foi conduzido em vinhedo da cultivar Vênus localizada no município de Urânia-SP, região noroeste do Estado de São Paulo, nos anos de 1999 e 2000. As videiras, em $2^{\circ}$ e $3^{\circ}$ anos de produção, eram enxertadas sobre o porta-enxerto IAC-572 e encontravam-se no espaçamento $5 \times 2 \mathrm{~m}$, e eram conduzidas no sistema de pérgula.

Nos dois anos de estudos, utilizaram-se thidiazuron a 5 ou $10 \mathrm{mg} . \mathrm{L}^{-1}$ e ácido giberélico a $30 \mathrm{mg} . \mathrm{L}^{-1}$, combinados ou não. Dessa forma, os tratamentos foram os seguintes:

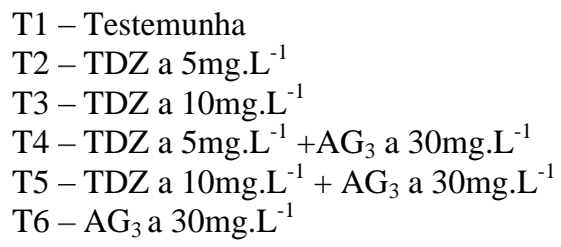

Todas as práticas culturais no vinhedo, exceto a utilização de ácido giberélico, foram idênticas ao siste- 
ma convencional da propriedade para toda a área experimental.

Os tratamentos com reguladores de crescimento foram efetuados, mediante única imersão dos cachos na solução contida em recipiente plástico, adicionada de espalhante adesivo Iharaguen- $\mathrm{S}^{\circledR}$ a $1 \%$, formulação comercial com $20 \%$ de polioxietileno alquilfenol éter. Para o preparo das soluções com reguladores de crescimento, utilizaram-se os produtos comerciais Dropp ${ }^{\circledR}$, com $50 \%$ de thidiazuron, e Pro-Gibb ${ }^{\circledR}$, com $10 \%$ de ácido giberélico.

O delineamento experimental foi em blocos casualizados com 7 repetições e 2 cachos por parcela. Videiras semelhantes em vigor foram selecionadas para cada bloco, numa mesma linha de plantio, e os cachos foram sorteados dentro de cada um dos 6 blocos, para a realização dos tratamentos.

A coleta dos cachos foi realizada aos 100 dias após a poda, em 8 de agosto de 1999, e aos 119 dias após a poda, em 27 de junho de 2000, quando o tratamento-testemunha atingiu o ponto de colheita comercial, ou seja, com teor de sólidos solúveis totais mínimo de $14,0^{\circ}$ Brix (CEAGESP, 2000). Posteriormente os cachos foram acondicionados em sacos de polietileno, devidamente identificados, transportados em caixas plásticas para o Instituto Agronômico de Campinas, onde foram mantidos em câmara frigorífica à temperatura de $3^{\circ} \mathrm{C}$ durante o período de avaliação.

Foram determinadas as seguintes variáveis:

1. Massa dos cachos, bagos e engaços, em balança de precisão. Após a medição da massa dos cachos, os bagos foram separados dos pedicelos, cortados com tesoura, para posterior pesagem dos bagos e engaços, separadamente.

2. Comprimento e largura dos cachos e bagos, com paquímetro digital. Para as medições das dimensões dos bagos, utilizou-se uma amostra de 20 bagos por cacho, calculando-se posteriormente a média de cada amostra.

3. Número de bagos por cacho.

4. Número de sementes-traço por bago (amostra de 20 bagos).

Para cada parcela, foram realizadas as seguintes análises do mosto de 100 bagos:

1. Teor de sólidos solúveis totais: com auxílio de refratômetro de mesa com autocompensação de temperatura (Carvalho et al., 1990);

2. Acidez total titulável: por titulação em uma alíquota de $5 \mathrm{ml}$ do mosto com $\mathrm{NaOH} 0,1 \mathrm{~N}$, e expressa em $\mathrm{g}$ de ácido tartárico por $100 \mathrm{ml}$ de mosto (Carvalho et al., 1990);

3. Relação teor de sólidos solúveis totais/acidez total titulável (SST/ATT).

Os resultados foram submetidos à análise de variância e comparação entre médias pelo teste de Duncan a $5 \%$ de probabilidade.

\section{RESULTADOS E DISCUSSÃO}

A maioria dos tratamentos com reguladores de crescimento aumentou a massa dos cachos de uvas 'Vênus', nos dois anos de estudo (Tabela 1). Os melhores resultados para essa variável foram verificados para os tratamentos combinados de thidiazuron e ácido giberélico, sem ter havido diferença significativa entre as duas doses de thidiazuron utilizadas. Não houve diferenças significativas para os resultados de comprimento e largura dos cachos (tabela 1); porém, quase que invariavelmente os maiores valores foram constatados para os tratamentos em que associaramse os dois reguladores de crescimento. Aumentos da massa, comprimento e largura de cachos promovidos por aplicações de ácido giberélico e thidiazuron também foram relatados por outros autores (Guerra et al., 1981; Pires et al., 1986; Reynolds et al., 1992 e Byun \& Kim, 1995).

$O$ efeito de reguladores de crescimento na massa dos bagos foi significativo somente no primeiro ano de estudo (Tabela 2). O aumento para essa variável foi constatado para aplicações de ácido giberélico, levando a incrementos de até $37,8 \%$ em relação à testemunha. Esse efeito do ácido giberélico não foi alterado quando associou-se thidiazuron. No segundo ano, não houve diferenças significativas entre os tratamentos para essa variável; porém, a tendência observada foi similar aos resultados obtidos no ano anterior.

Para os resultados de comprimento e largura dos bagos (Tabela 2), poucos tratamentos diferiram da testemunha; porém, os tratamentos com ácido giberélico, associado ou não ao thidiazuron, apresentaram os maiores valores para essas variáveis. A aplicação de ácido giberélico de forma isolada aumentou significativamente o comprimento dos bagos nos dois anos de estudo, e a largura dos bagos, em 1999. O tratamento com ácido giberélico, associado a thidiazuron a $5 \mathrm{mg} . \mathrm{L}^{-1}$, aumentou a largura dos bagos, em 2000.

Ciênc. agrotec., Lavras. V.27, n.2, p.312-318, mar./abr., 2003 
TABELA 1 - Massa, comprimento e largura dos cachos de uvas do cultivar Vênus tratadas com thidiazuron e ácido giberélico (Urânia-SP).

\begin{tabular}{|c|c|c|c|c|c|c|}
\hline \multirow{2}{*}{ Tratamentos $^{1}$} & \multicolumn{2}{|c|}{ Massa cachos (g) } & \multicolumn{2}{|c|}{ Comprimento cachos $(\mathbf{c m})$} & \multicolumn{2}{|c|}{ Largura cachos $(\mathrm{cm})$} \\
\hline & 1999 & 2000 & 1999 & 2000 & 1999 & 2000 \\
\hline Testemunha & $174,0 \quad d^{2}$ & $447,8 \mathrm{~cd}$ & 15,58 & 17,94 & 10,50 & 12,46 \\
\hline TDZ 5 & $285,6 \mathrm{~b}$ & $422,7 \quad d$ & 17,62 & 18,16 & 10,58 & 11,81 \\
\hline TDZ 10 & $243,2 \quad c$ & $521,0 \mathrm{abc}$ & 15,82 & 19,05 & 10,12 & 12,67 \\
\hline $\mathrm{TDZ} 5+\mathrm{AG}_{3}$ & $396,0 \mathrm{a}$ & $602,2 \mathrm{a}$ & 16,24 & 18,28 & 11,14 & 13,30 \\
\hline $\mathrm{TDZ} 10+\mathrm{AG}_{3}$ & $403,4 a$ & $556,0 \mathrm{ab}$ & 17,78 & 19,03 & 11,40 & 13,98 \\
\hline $\mathrm{AG}_{3}$ & $363,0 \mathrm{a}$ & $492,5 \mathrm{bcd}$ & 17,40 & 17,08 & 10,98 & 12,23 \\
\hline C.V. $(\%)$ & 10,12 & 14,54 & 13,91 & 14,08 & 11,14 & 14,48 \\
\hline
\end{tabular}

${ }^{1}$ TDZ 5 = thidiazuron 5mg.L $\mathrm{L}^{-1}$ TDZ 10 = thidiazuron 10mg.L ${ }^{-1} ; \mathrm{AG}_{3}=$ ácido giberélico 30mg.L-1

${ }^{2}$ Médias seguidas pela mesma letra, numa mesma coluna, não diferem entre si pelo teste de Duncan a $5 \%$ de probabilidade.

TABELA 2 - Massa, comprimento e largura dos bagos de uvas do cultivar Vênus tratadas com thidiazuron e ácido giberélico (Urânia-SP).

\begin{tabular}{lcccccc}
\hline \multirow{2}{*}{ Tratamentos $^{1}$} & \multicolumn{3}{c}{ Massa bagos $(\mathbf{g})$} & \multicolumn{2}{c}{ Comprimento bagos $(\mathbf{m m})$} & \multicolumn{2}{c}{ Largura bagos (mm) } \\
\cline { 2 - 7 } & $\mathbf{1 9 9 9}$ & $\mathbf{2 0 0 0}$ & $\mathbf{1 9 9 9}$ & $\mathbf{2 0 0 0}$ & $\mathbf{1 9 9 9}$ & $\mathbf{2 0 0 0}$ \\
\hline Testemunha & $2,30 \mathrm{~cd}^{2}$ & 3,03 & $16,48 \mathrm{~b}$ & $19,03 \mathrm{bc}$ & $15,71 \mathrm{~b}$ & $17,16 \mathrm{bc}$ \\
TDZ 5 & $2,58 \mathrm{bcd}$ & 3,08 & $16,99 \mathrm{ab}$ & $18,56 \mathrm{c}$ & $16,48 \mathrm{ab}$ & $16,61 \mathrm{c}$ \\
TDZ 10 & $2,23 \mathrm{~d}$ & 3,12 & $17,37 \mathrm{ab}$ & $19,15 \mathrm{bc}$ & $16,52 \mathrm{ab}$ & $17,75 \mathrm{abc}$ \\
TDZ 5 $+\mathrm{AG}_{3}$ & $2,93 \mathrm{ab}$ & 3,63 & $18,27 \mathrm{ab}$ & $20,90 \mathrm{ab}$ & $16,78 \mathrm{ab}$ & $18,58 \mathrm{a}$ \\
TDZ 10+ $\mathrm{AG}_{3}$ & $2,84 \mathrm{abc}$ & 3,74 & $17,84 \mathrm{ab}$ & $20,40 \mathrm{abc}$ & $16,85 \mathrm{ab}$ & $17,92 \mathrm{ab}$ \\
$\mathrm{AG}_{3}$ & $3,17 \mathrm{a}$ & 3,60 & $18,43 \mathrm{a}$ & $21,32 \mathrm{a}$ & $16,97 \mathrm{a}$ & $17,98 \mathrm{ab}$ \\
$\mathrm{C} . \mathrm{V} .(\%)$ & 15,29 & 19,69 & 8,06 & 7,65 & 5,58 & 5,17 \\
\hline
\end{tabular}

${ }^{1}$ TDZ 5 = thidiazuron 5mg.L ${ }^{-1} ;$ TDZ $10=$ thidiazuron 10mg. $\mathrm{L}^{-1} ; \mathrm{AG}_{3}=$ ácido giberélico 30mg ${ }^{\mathrm{L}-1}$

${ }^{2}$ Médias seguidas pela mesma letra, numa mesma coluna, não diferem entre si pelo teste de Duncan a $5 \%$ de probabilidade.

Segundo Métraux (1988), o crescimento de órgãos vegetais promovido por giberelinas deve-se principalmente a um aumento do tamanho de células já existentes ou recentemente divididas. Porém, esse crescimento das células pode ser acompanhado por um incremento do número de células.

De acordo com McGraw (1988), citocininas também podem promover o crescimento de órgãos vegetais pelo estímulo da divisão celular; porém, a- plicações de thidiazuron não foram efetivas no aumento do tamanho dos bagos de uvas 'Vênus', não estando de acordo com os resultados obtidos por Reynolds et al. (1992). Possivelmente, as doses utilizadas neste trabalho não foram adequadas para promover o crescimento dos bagos.

No primeiro ano de estudo, todos os tratamentos com reguladores de crescimento levaram ao aumento do número de bagos (Tabela 3), e os maiores aumentos fo- 
ram verificados para os tratamentos em que associou-se thidiazuron e ácido giberélico. No entanto, em 2000, não houve diferenças significativas para essa variável.

Aparentemente, em 1999, tanto o thidiazuron como o ácido giberélico promoveram o pegamento de frutos e, quando aplicados conjuntamente, apresentaram efeito aditivo. Byun \& Kim (1995) também verificaram aumento do número de bagos de cachos de uvas da cultivar Kyoho tratadas com thidiazuron. Segundo Hayata et al. (1995), substâncias com ação de citocinina podem promover o pegamento de frutos devido ao seu efeito em atrair nutrientes para os órgãos tratados, aumentando a habilidade dos frutos jovens em competir por assimilados com o resto da planta.

Em vinhedos de 'Concord', onde ocorre queda precoce dos bagos, esse problema pode ser mimimizado aplicando-se solução aquosa de $\mathrm{AG}_{3}$ a $100 \mathrm{mg} . \mathrm{L}^{-1}, 11$ dias após o florescimento (Bukovac et al.; 1960). Segundo Pires (1998), a giberelina pode funcionar como indutor da formação de enzimas proteolíticas, as quais podem liberar triptofano, precursor do ácido indol acético, evitando a abscisão dos bagos.

Nos dois anos de estudo, aplicações de reguladores de crescimento reduziram o número de sementestraço por bago (Tabela 3). Aparentemente, houve efeito aditivo de thidiazuron e ácido giberélico para essa variável. Redução no número de sementes também foi verificada por Petri et al. (1992), quando aplicaram thidiazuron em maçãs, o que foi relacionado ao desenvolvimento de frutos parternocárpicos. Segundo Itakura et al (1965), a ausência de sementes induzida pelo ácido giberélico é causada, principalmente, pelos efeitos nocivos que essa substância tem sobre os óvulos.

Apenas o tratamento com thidiazuron a $10 \mathrm{mg} . \mathrm{L}^{-}$ ${ }^{1}$ aumentou significativamente a massa dos engaços, no primeiro ano de estudo (Tabela 3). No entanto, todos os tratamentos com reguladores de crescimento apresentaram massa dos engaços superiores ao da testemunha. Aumentos da massa dos engaços promovidos pela aplicação de ácido giberélico e thidiazuron também foram verificados por Pires et al. (1986) e por Reynolds et al. (1992).

No segundo ano de estudo, aplicações de thidiazuron a $10 \mathrm{mg} . \mathrm{L}^{-1}$, associado ou não ao ácido giberélico, reduziram significativamente o teor de sólidos solúveis totais do mosto de uvas 'Vênus' (Tabela 4). Em 1999, não houve diferenças significativas, porém, os dois tra- tamentos em que aplicou-se thidiazuron a $10 \mathrm{mg} \cdot \mathrm{L}^{-1} \mathrm{a}$ presentaram os menores valores para essa variável.

Os tratamentos com thidiazuron a $10 \mathrm{mg} . \mathrm{L}^{-1}$, associado ou não ao ácido giberélico, aumentaram significativamente a acidez total titulável do mosto de uvas 'Vênus' em pelo menos um dos anos de estudo (Tabela 4).

Redução do teor de sólidos solúveis totais e aumento da acidez total titulável do mosto de uvas tratadas com thidiazuron foram também relatados por Reynolds et al. (1992) e por Byun \& Kim (1995). Segundo McGraw (1988), citocininas podem atrasar a senescência de órgãos vegetais, o que está relacionado a modificações na síntese protéica e à ativação de enzimas. O efeito do thidiazuron no atraso da maturação pôde também ser observado pela redução da relação SST/ATT dos tratamentos que incluíram aplicações de thidiazuron a 10 mg. $\mathrm{L}^{-1}$.

Ficou evidente a possibilidade de utilização de ácido giberélico para aumentar o tamanho dos bagos de uvas da cultivar Vênus. Nas condições deste trabalho, a aplicação de ácido giberélico a $30 \mathrm{mg} . \mathrm{L}^{-1}$, por imersão dos cachos 14 dias após o pleno florescimento, promoveram aumento entre $37,8 \%$ e $18,8 \%$ da massa dos bagos. Adicionalmente, esse regulador de crescimento promoveu o maior pegamento dos bagos e a redução do número de sementes-traço.

A associação com thidiazuron potencializou os efeitos do ácido giberélico no aumento do número de bagos e na redução do número de sementes-traço. $\mathrm{O}$ maior pegamento dos frutos pode ser conveniente nos anos em que as condições climáticas não são ideais para polinização, visto que esse efeito está relacionado ao desenvolvimento de frutos partenocárpicos e, portanto, sem a sua devida polinização.

A cultivar 'Vênus', apesar de ser denominada como sendo sem sementes, não pode ser considerada como tal em termos comerciais, porque apresenta sementes-traço com o embrião abortado. Dessa forma, a redução do número de sementes-traço é bastante interessante para a melhoria da qualidade de uvas 'Vênus'. Novos estudos deverão ser conduzidos buscando um tratamento que possibilite a total eliminação dessas sementes-traço indesejáveis.

Aplicações de thidiazuron a $10 \mathrm{mg} . \mathrm{L}^{-1}$ atrasaram a maturação dos cachos, o que pode ser uma boa estratégia comercial, possibilitando um escalonamento da colheita para épocas em que não existe oferta abundante do produto. 
TABELA 3 - Número de bagos, número de sementes, e massa dos engaços de uvas da cultivar Vênus tratadas com thidiazuron e ácido giberélico (Urânia-SP).

\begin{tabular}{lcccccc}
\hline \multirow{2}{*}{ Tratamentos $^{1}$} & \multicolumn{2}{c}{ Número bagos } & \multicolumn{2}{c}{ Número sementes-traço } & \multicolumn{2}{c}{ Massa engaços (g) } \\
\cline { 2 - 7 } & $\mathbf{1 9 9 9}$ & $\mathbf{2 0 0 0}$ & $\mathbf{1 9 9 9}$ & $\mathbf{2 0 0 0}$ & $\mathbf{1 9 9 9}$ & $\mathbf{2 0 0 0}$ \\
\hline Testemunha & $75,6 \mathrm{c}$ & 145,7 & $1,52 \mathrm{a}$ & $2,13 \mathrm{a}$ & $2,64 \mathrm{~b}$ & 5,31 \\
TDZ 5 & $109,4 \mathrm{~b}$ & 137,6 & $1,07 \mathrm{ab}$ & $1,00 \mathrm{~b}$ & $3,17 \mathrm{~b}$ & 5,66 \\
TDZ 10 & $107,4 \mathrm{~b}$ & 152,2 & $0,75 \mathrm{~b}$ & $0,96 \mathrm{~b}$ & $6,61 \mathrm{a}$ & 6,41 \\
TDZ 5 + AG & $133,8 \mathrm{ab}$ & 160,0 & $0,52 \mathrm{~b}$ & $0,12 \mathrm{c}$ & $4,00 \mathrm{~b}$ & 6,68 \\
TDZ 10+ $\mathrm{AG}_{3}$ & $142,6 \mathrm{a}$ & 149,2 & $0,77 \mathrm{~b}$ & $0,10 \mathrm{c}$ & $4,51 \mathrm{ab}$ & 6,51 \\
$\mathrm{AG}_{3}$ & $112,4 \mathrm{~b}$ & 138,8 & $1,00 \mathrm{ab}$ & $0,93 \mathrm{~b}$ & $3,63 \mathrm{~b}$ & 5,90 \\
C.V. $(\%)$ & 17,60 & 22,40 & 59,12 & 40,78 & 39,76 & 24,42 \\
\hline
\end{tabular}

${ }^{1}$ TDZ 5 = thidiazuron $5 \mathrm{mg} . \mathrm{L}^{-1}$; TDZ $10=$ thidiazuron $10 \mathrm{mg} \mathrm{L}^{-1} ; \mathrm{AG}_{3}=$ ácido giberélico 30mg ${ }^{\mathrm{L}-1}$

${ }^{2}$ Médias seguidas pela mesma letra, numa mesma coluna, não diferem entre si pelo teste de Duncan a $5 \%$ de probabilidade.

TABELA 4 - Teor de sólidos solúveis totais, acidez total titulável e relação SST/ATT do mosto de uvas do cultivar Vênus tratadas com thidiazuron e ácido giberélico (Urânia-SP).

\begin{tabular}{lcccccc}
\hline \multirow{2}{*}{ Tratamentos $^{1}$} & \multicolumn{2}{c}{ Sólidos Solúveis totais $(\%)$} & \multicolumn{2}{c}{$\begin{array}{c}\text { Acidez total titulável } \\
\text { (g ácido tartárico/100ml) }\end{array}$} & \multicolumn{2}{c}{ Relação SST/ATT } \\
\cline { 2 - 7 } & $\mathbf{1 9 9 9}$ & $\mathbf{2 0 0 0}$ & $\mathbf{1 9 9 9}$ & $\mathbf{2 0 0 0}$ & $\mathbf{1 9 9 9}$ & $\mathbf{2 0 0 0}$ \\
\hline Testemunha & 15,10 & $15,80 \mathrm{a}$ & $0,768 \mathrm{ab}$ & $0,788 \mathrm{~b}$ & $19,55 \mathrm{ab}$ & $20,89 \mathrm{a}$ \\
TDZ 5 & 15,28 & $14,04 \mathrm{ab}$ & $0,725 \mathrm{~b}$ & $0,780 \mathrm{~b}$ & $21,21 \mathrm{a}$ & $18,48 \mathrm{a}$ \\
TDZ 10 & 14,13 & $11,22 \mathrm{c}$ & $0,822 \mathrm{a}$ & $0,929 \mathrm{a}$ & $17,16 \mathrm{~b}$ & $12,48 \mathrm{~b}$ \\
TDZ 5 $+\mathrm{AG}_{3}$ & 14,43 & $14,54 \mathrm{ab}$ & $0,730 \mathrm{~b}$ & $0,764 \mathrm{~b}$ & $19,27 \mathrm{ab}$ & $19,69 \mathrm{a}$ \\
TDZ 10+ $\mathrm{AG}_{3}$ & 14,02 & $12,80 \mathrm{bc}$ & $0,828 \mathrm{a}$ & $0,814 \mathrm{~b}$ & $16,97 \mathrm{~b}$ & $16,69 \mathrm{ab}$ \\
$\mathrm{AG}_{3}$ & 14,96 & $14,48 \mathrm{ab}$ & $0,802 \mathrm{a}$ & $0,734 \mathrm{~b}$ & $19,14 \mathrm{ab}$ & $20,09 \mathrm{a}$ \\
$\mathrm{C} . \mathrm{V} .(\%)$ & 11,74 & 15,84 & 8,49 & 11,55 & 11,74 & 25,65 \\
\hline
\end{tabular}

${ }^{1}$ TDZ 5 = thidiazuron 5mg. $\mathrm{L}^{-1}$; TDZ $10=$ thidiazuron $10 \mathrm{mg} . \mathrm{L}^{-1} ; \mathrm{AG}_{3}=$ ácido giberélico 30mg.t-1

${ }^{2}$ Médias seguidas pela mesma letra, numa mesma coluna, não diferem entre si pelo teste de Duncan a $5 \%$ de probabilidade.

\section{CONCLUSÕES}

a) Aplicação de ácido giberélico a $30 \mathrm{mg} . \mathrm{L}^{-1}$, aos 14 dias após o pleno florescimento, aumentou a massa e o número de bagos e reduziu o número de sementestraço em uvas do cultivar Vênus.

b) Aplicação de thidiazuron a $10 \mathrm{mg} . \mathrm{L}^{-1}$, aos 14 dias após o pleno florescimento, aumentou o número de bagos, reduziu o número de sementes-traço e atrasou a maturação de uvas da cultivar Vênus. c) Houve efeito sinérgico entre ácido giberélico e thidiazuron para as variáveis número de bagos e de sementes-traço.

\section{AGRADECIMENTOS}

Ao Sr. Valdeir Biundes Hermoso e à Sra. Maria das Graças dos Santos Lima, pelo empenho e dedicação na condução e avaliação dos experimentos. 


\section{REFERÊNCIAS BIBLIOGRÁFICAS}

AGRIANUAL 2001. São Paulo: FNP Consultoria \& Comércio, 2001. p. 532-545.

BUKOVAC, L. D.; LARSEN, R. P., BELL, H. K. Effect of gibberellin on berry set and development of Concord grapes. Quartely Bulletin of Michigan Agriculture Experimental Station, Michigan, v. 42, p. 503-510, 1960.

BYUN, J. K., KIM, J. S. Effects of $\mathrm{GA}_{3}$, thidiazuron and ABA on fruit set and quality of 'Kyoho' grapes. Journal of the Korean Society for Horticultural Science, Alexandria, v. 36, n. 2, p. 231-239, 1995.

CARVAlHO, C. R. L., CARVAlHO, P. R. N.; MANTOVANI, D. M. B.; MORAES, R. M. Análise química de alimentos. Campinas: ITAL, 1990. 121 p.

CEAGESP. Classificação da uva (Vitis vinifera L.). São Paulo: CQH/CEAESP, 2000. (Programa brasileiro para melhoria dos padrões comerciais e embalagens de hortigranjeiros).

FRANCISCONI, A. H. D., BARRADAS, C. I. N., MARODIN, G. A. B., SEIBERT, E. Efeito de óleo mineral, cianamida hidrogenada e thidiazuron na quebra de dormência e produção da pereira (Pyrus communis L.) cv. Packham's Triumph. Revista Brasileira de Fruticultura, Cruz das Almas, v. 14, n. 1, p. 161-166, 1992.

GUERRA, M. P., BARCELlOS, F. M., KOLLER, O. C. Influência do ácido giberélico, aplicado em floração e pós-floração, sobre as características do cacho da videira Itália (Vitis vinifera L.). In: CONGRESSO BRASILEIRO DE FRUTICULTURA, 6., 1981, Recife. Anais... Recife: Sociedade Brasileira de Fruticultura, 1981. v. 4, p. 1278-1286.

HAYATA, Y., NIIMI, Y., IWASAKI, N. Synthetic citokinin - 1-(2-chloro-4-pyridyl)-3-phenylurea (CPPU) promotes fruit set and induces parthenocarpy in watermelon. Journal of the American Society for Horticultural Science, Alexandria, v. 120, n. 6, p. 997-1000, 1995.

ITAKURA, T., KIZAKI, I., MACHIDA, Y. Studies with gibberellin application in relation to response of certain grape varieties. Horticultural Research Station- Ministery of Agriculture and Forestry of Japan, Hiratsuka, Series A, n. 4, p. 67-95, 1965.

MACGRAW, B. A. Cytokinin biosynthesis and metabolism. In: DAVIES, P. J. Plant hormones and their role in plant growth and development. 2. ed. Dordrecht: Kluwer Academic Publishers, 1988. p. 7693.

MÉTRAUX, J. P. Gibberellins and plant cell elongation. In: DAVIES, P. J. Plant hormones and their role in plant growth and development. 2. ed. Dordrecht: Kluwer Academic Publishers, 1988. p. 296317.

PETRI, J. L., ARGENTA, L. C., SUZUKI, A. Efeitos do thidiazuron no tamanho e desenvolvimento dos frutos da macieira. Revista Brasileira de Fruticultura, Cruz das Almas, v. 14, n. 2, p. 127-134, 1992.

PIRES, E. J. P. Emprego de reguladores de crescimento em viticultura tropical. Informe Agropecuário, Belo Horizonte, v. 19, n. 194, p. 34-39, 1998.

PIRES, E. J. P., FAHL, J. I., CARELli, M. L. C., TERRA, M. M., PASSOS, I. R. S., CRUZ, L. S. P., MARTINS, F. P. Respostas a aplicação de ácido giberélico (GA) em panículas de videira do cultivar IAC 871-13 A Dona. In: CONGRESSO BRASILEIRO DE FRUTICUlTURA, 8., 1986, Brasília. Anais... Brasília: Embrapa-DDT/Cnpq, 1986. v. 2, p. 473-477.

REYNOLDS, A. G., WARDLE, D. A., ZUROWSKI, C., LOONEY, N. E. Phenylureas CPPU and thidiazuron affect yield components, fruit composition, and storage potential of four seedless grape selections. Journal of the American Society for Horticultural Science, Alexandria, v. 117, n. 1, p. 85-89, 1992.

SCHUCK, E., PETRI, J. L. Efeitos do thidiazuron no peso médio dos frutos de quivi. Revista Brasileira de Fruticultura, Cruz das Almas, v. 14, n. 2, p. 185-188, 1992.

TERRA, M. M., PIRES, E. J. P., NOGUEIRA, N. A. M. Tecnologia para produção de uva Itália na região noroeste do Estado de São Paulo. Campinas: Coordenadoria de Assistência Técnica Integral, 1998. 51 p. (Documento Técnico, 97). 